This item was submitted to Loughborough's Research Repository by the author.

Items in Figshare are protected by copyright, with all rights reserved, unless otherwise indicated.

\title{
Effect of ultrasonically-assisted drilling on carbon-fibre-reinforced plastics
}

PLEASE CITE THE PUBLISHED VERSION

http://dx.doi.org/10.1016/j.jsv.2014.05.042

\section{PUBLISHER}

(c) Elsevier

VERSION

AM (Accepted Manuscript)

\section{PUBLISHER STATEMENT}

This work is made available according to the conditions of the Creative Commons Attribution-NonCommercialNoDerivatives 4.0 International (CC BY-NC-ND 4.0) licence. Full details of this licence are available at: https://creativecommons.org/licenses/by-nc-nd/4.0/

\section{LICENCE}

CC BY-NC-ND 4.0

\section{REPOSITORY RECORD}

Makhdum, Farrukh, Vaibhav A. Phadnis, Anish Roy, and Vadim V. Silberschmidt. 2019. "Effect of Ultrasonically-assisted Drilling on Carbon-fibre-reinforced Plastics". figshare.

https://hdl.handle.net/2134/15910. 


\title{
Effect of ultrasonically-assisted drilling on carbon-fibre-reinforced plastics
}

\author{
Farrukh Makhdum, Vaibhav A. Phadnis, Anish Roy, Vadim V. Silberschmidt*
}

Wolfson School of Mechanical and Manufacturing Engineering, Loughborough University, Loughborough, LE11 3TU, UK

\author{
*Corresponding author: Vadim V. Silberschmidt, Tel: +44 (0) 1509227 504, \\ Email:v.silberschmidt@lboro.ac.uk
}

\begin{abstract}
This research focuses on the effect of ultrasonically-assisted drilling (UAD) on carbon fibrereinforced plastics. High-frequency vibration was used to excite a drill bit during its standard operation. An extensive experimental study of drilling forces, temperature, chip formation, surface finish, circularity, delamination and tool wear, was conducted using $\varnothing 3 \mathrm{~mm}$ drill and presented here. UAD showed a significant improvement in drill quality when compared to conventional drilling processes. A finite-element study was also conducted to understand the nature of drilling-force reduction in UAD.
\end{abstract}

Keywords: Ultrasonic vibration; drilling; force reduction; tool wear; delamination; CFRP; finite-element analysis

\section{Introduction}

Carbon-fibre-reinforced plastic (CFRP) composites have strong but brittle carbon fibres embedded into a weaker plastic matrix. The carbon fibres support the load, while the matrix serves to hold and protect the fibres and transmit the load to them. CFRP composites have many superior properties including low density (lower than aluminium), high strength (as high-strength steels), high stiffness (stiffer than titanium), good fatigue and creep resistance, and excellent dimensional stability (close to zero coefficient of thermal expansion). Thus, it is of no surprise that CFRP composites are widely used as structural and functional components in aerospace, biomedical, sports, automotive and defence applications amongst others.

Though every attempt is made to manufacture CFRP components to near-net shape, in order to facilitate their assembly, machining of CFRP is unavoidable. For example, to join structures, holes need to be drilled to facilitate riveting and bolting. Thus, drilling in 
composites is indispensable. However, this process leads to various damage modes in composites, such as delamination, fibre pull-out, hole-roundness errors and inter-laminar crack propagation. Amongst these, delamination is a major threat, as it leads to a loss of mechanical and fatigue strength in the drilled-hole area [1]. Hocheng and Tsao [2, 3] explored the possibilities of delamination-free drilling in composite materials via an exhaustive study of drill types and defining the level of critical thrust force at the onset of delamination. Apparently, reduction of this force can diminish the extent of drilling-induced damage. Hence, it was realised that vibration assisted drilling has potential as a viable nontraditional drilling method for damage free drilling in heterogeneous composites $[4,5,6,7]$.

In the recent past $[8,9,11]$, ultrasonically-assisted drilling (UAD) techniques, in which highfrequency (typically $>18 \mathrm{kHz}$ ) and low-amplitude $(<20 \mu \mathrm{m}$ ) vibration was superimposed on a movement of a standard twist drill bit in the axial direction, has been used to improve the overall machinability of advanced materials. These studies were typically performed using $\varnothing 6 \mathrm{~mm}$ and wider drills in a variety of workpiece materials including metals and woven composites. Several studies performed over the last few years indicated that vibrating the drill bit in the axial direction yielded the maximum reduction in drilling-induced damage. There are several well-documented advantages of UAD over conventional drilling (CD) techniques such as reduction in thrust forces and torque, better surface finish, low tool wear and elimination/reduction in burr formation $[8,9,10,11]$. The thrust force has a direct effect on drilling-induced damage in composites; hence, it is considered to be the main parameter affecting quality of a drilled hole.

The paper is organized as follows. In Section 2, descriptions of the experimental setup including various characterisation instruments used are presented along with details of a workpiece material and cutting tools used. Section 3 comprises measurement results followed by discussions in Section 4. The paper ends with some concluding remarks in Section 5 .

\section{Experimental work}

\subsection{Experimental setup}

A universal lathe (Harrison M-300) was modified to accommodate an ultrasonic transducer (Fig. 1), and the modified system offered flexibility of conducting UAD and CD experiments 
using the same setup. It comprises of a Langevin-type piezoelectric ultrasonic transducer that uses a high-frequency alternating voltage to create mechanical vibration by employing piezoelectric effects.

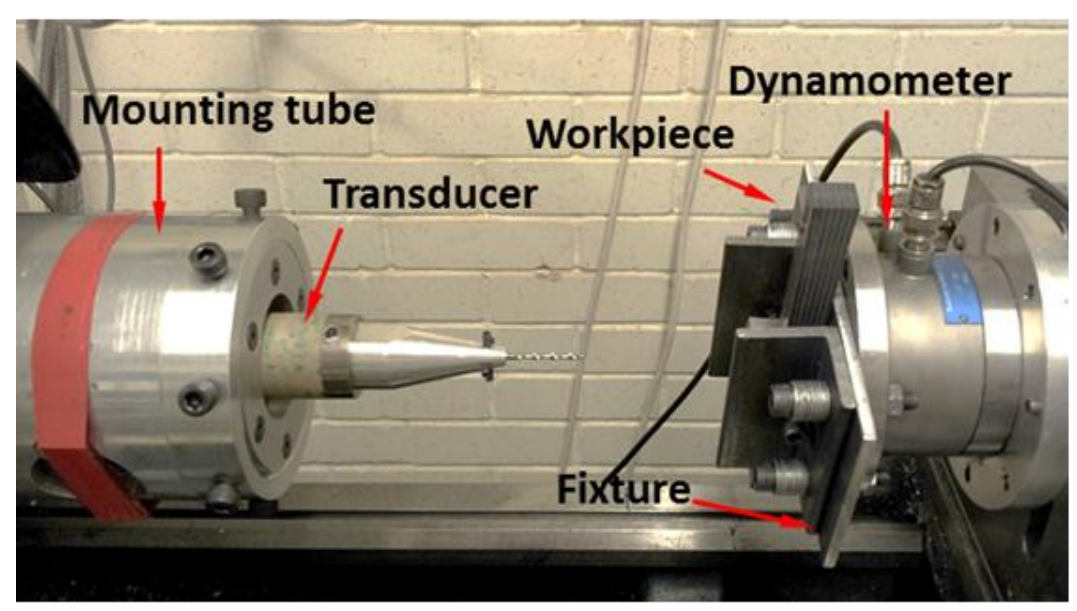

(a)

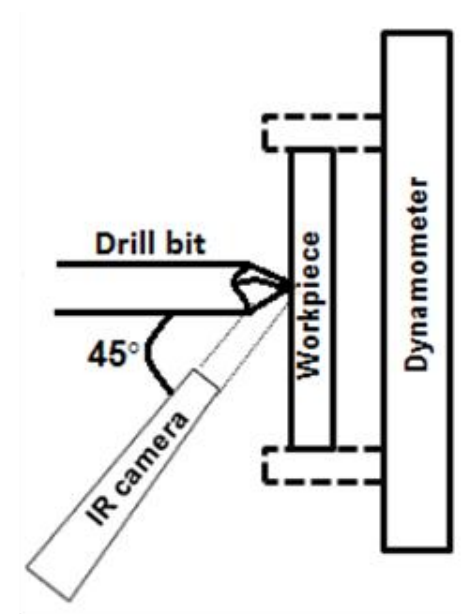

(b)

Figure 1. Experimental setup (a); schematic for temperature measurements (b)

A typical transducer consists of a stack of peizoceramic elements, a front wave-guide and a backing mass. The vibration amplitude generated in the piezoelectric element is too small for viable applications; hence, geometry of the transducer's components needs to be appropriately designed with the aid of eigen mode analysis to amplify the amplitudes [12]. Thus, a commercially available transducer was appropriately modified using an improved design of its waveguide to accommodate a $\varnothing 3 \mathrm{~mm}$ drill bit. The waveguide design was carried out based on the modal analysis with a commercial finite-element software Abaqus v6.11 [13] in order to maximise the amplitude of the longitudinal (axial) mode of vibration.

The waveguide was made of aluminium as it provides a fair degree of acoustic coupling between a carbide drill bit and a steel transducer horn. The transducer was fastened in an aluminium tube and mounted on the headstock of the lathe using a four-jaw universal chuck (see Fig. 1a). The conical waveguide was screwed on the transducer horn. Precautionary measures were taken during the overall assembly of the system to ensure rigidity of the complete system. Thus, the headstock of the lathe accommodated the transducer assembly; whereas, the tail stock of the lathe was prepared to accommodate a workpiece and a forcemeasuring dynamometer. In UAD experiments, the frequency was tuned and set at a 
particular resonance level with the help of GW Instek $^{\mathrm{TM}}$ (model SFG-2110) functional generator.

Langevin transducers usually have one or two resonant frequencies where substantial vibration amplitudes may be achieved. In this work, the transducer was designed to resonate at frequencies in excess of $20 \mathrm{kHz}$. We observe only one resonance frequency for this transducer with the attached drill bit at a frequency of $27.8 \mathrm{kHz}$.

\subsection{Workpiece material}

The workpiece material used in the drilling studies was a M21/T700 CFRP provided by Airbus $^{\mathrm{TM}}$. This quasi-isotropic composite was composed of 34 plies with the stacking sequence of $\left[\left(0^{\circ} / 45^{\circ} / 90^{\circ} /-45^{\circ}\right)_{4 s} / 0^{\circ}\right]_{s}$, shown in Fig. 2. The plates of CFRP (thickness: $10 \mathrm{~mm}$ ) were cut into pieces with a length of $200 \mathrm{~mm}$; and width of $10 \mathrm{~mm}$. The composite material was tested and mechanical properties were evaluated via a series of experiments conducted at the in-house materials-testing facility in Loughborough University, UK. The mechanical properties of the unidirectional $0^{\circ}$ ply (all the fibres in loading direction) are given in Table 1; further details are available in [14].

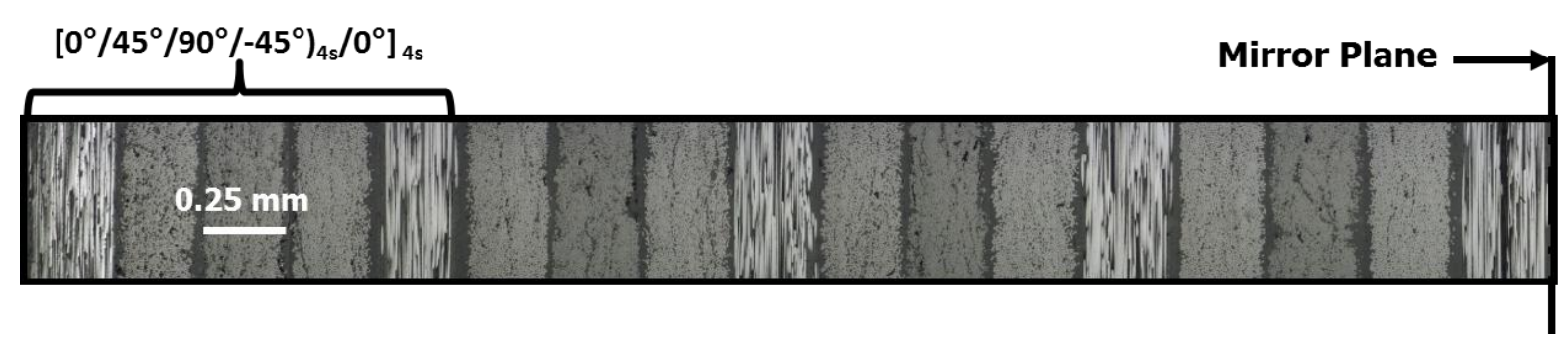

Figure 2: Optical microscopy of workpiece's stacking order

Table 1: Mechanical properties of workpiece (CFRP)

\begin{tabular}{ccccc}
\hline $\mathrm{E}_{11}(\mathrm{GPa})$ & $\mathrm{E}_{22}=\mathrm{E}_{33}(\mathrm{GPa})$ & $\mathrm{v}_{12}=\mathrm{v}_{13}$ & $\mathrm{G}_{12}=\mathrm{G}_{13}(\mathrm{GPa})$ & $\mathrm{G}_{23}(\mathrm{GPa})$ \\
\hline 115 & 14 & 0.29 & 4 & 3.2 \\
\hline
\end{tabular}

\subsection{Drilling tool}

Drilling tests were conducted using a Jobber carbide two-flute, TiN coated, $\varnothing 3 \mathrm{~mm}$ twist drill with a point angle of $118^{\circ}$. Its helix angle was measured as $31^{\circ}$. The TiN coating helps to mitigate tool wear - an important feature since the carbon fibres are highly abrasive. The transducer design accounted for the exact drill geometry in order to maximise the 
amplitude of longitudinal vibration in UAD at the drill tip. This amplitude was monitored in free-vibration mode using a laser vibrometer.

\subsection{Instrumentation}

\subsubsection{Measurement of drilling forces}

An angle plate was fixed on the cross-slide of the lathe machine, with a two-channel Kistler $^{\mathrm{TM}}$ (Model 9271A) dynamometer bolted to it. The dynamometer was capable of measuring the thrust force and torque during the drilling process up to $20 \mathrm{kN}$ and $10 \mathrm{kN}-\mathrm{cm}$, respectively, with a maximum acquisition frequency of $3 \mathrm{kHz}$. Since this frequency is significantly lower than that of the imposed ultrasonic vibration during UAD, an average level of drilling forces was acquired during the machining process. A special fixture was fabricated and mounted on the dynamometer to accommodate the workpiece (see Fig. 1a). The dynamometer and the drill bit were aligned to be co-axial so that the levels of the thrust forces and torques could be recorded with a minimum error. A rotational speed was imposed on the drill bit (attached to the transducer) whereas an axial feed was imposed on the workpiece, allowing it to translate towards the drill bit.

Force signals from the dynamometer were amplified using a charge amplifier and converted and transmitted to the computer via an analogue-digital converter (digital oscilloscope Picoscope $\left.{ }^{\mathrm{TM}}\right)$. The acquired data were further processed using Matlab ${ }^{\mathrm{TM}}$ [15].

\subsubsection{Temperature measurement}

A thermal camera (FLIR ThermaCAM ${ }^{\mathrm{TM}}$ SC3000) was used for in-situ temperature measurement during the drilling process. The new Stirling-cooled Quantum Well Infrared Photodetector enabled the FLIR ThermaCAM system to capture the images at low-noise detection as well as high image stability and uniformity. The schematic of instrument's positioning is shown in Fig. 1b. The ThermaCAM ${ }^{\circledR}$ QuickView $^{\mathrm{TM}}$ software was used to analyse the data of the FLIR ThermaCAM ${ }^{\mathrm{TM}}$ SC3000 system. The emissivity of the workpiece and the drill bit were evaluated to be 0.29 and 0.27 respectively, which was then accounted for in the ThermaCAM software. The camera was also calibrated with the help of K-type thermocouples in order to record the data with minimum possible error. Further details of the system are listed in Table 2.

Table 2: Features of FLIR ThermaCAM 


\begin{tabular}{lr}
\hline Image Format (Pixel) & $320 \times 240$ \\
Temperature Range $\left({ }^{\circ} \mathrm{C}\right)$ & -20 to 2000 \\
Emissivity & 0.32 \\
Spectral range $(\mu \mathrm{m})$ & $8-9$ \\
Image frequency $(\mathrm{Hz})$ & $50 / 60$ \\
Accuracy $(\%)$ & \pm 2 above $150^{\circ} \mathrm{C}$ \\
\hline
\end{tabular}

\subsubsection{Measurement of vibration amplitude}

A Polytec ${ }^{\mathrm{TM}}$ laser vibrometer (model OFV-3001) was used to measure the vibration amplitude in UAD. The vibrometer was capable of monitoring vibration at a velocity of 10 $\mathrm{m} / \mathrm{s}$ with the resolution of $0.08 \mu \mathrm{m} / \mathrm{sec}$. The frequency and amplitude were tuned for the drill tip in free vibration as it is not possible to do this once the drilling process starts because of the lack of direct line of sight once the drill tip is fully engaged in the workpiece. All the experiments were conducted at the tuned frequency and amplitude.

\subsubsection{Surface Metrology}

Post-drilling analysis of the workpiece was conducted to evaluate the quality of drilling process, in particular, hole circularity and surface roughness of the hole as well as delamination in the composite. In addition, tool wear was also studied. To determine hole circularity, the Metris LK Ultra 627134 CMM with SP25 $\varnothing 1 \mathrm{~mm}$ stylus was used. The samples were positioned on the base-table of the CMM with the entrance face upwards. The specimens were levelled and circularity was measured at the depth of $5 \mathrm{~mm}$ and $8 \mathrm{~mm}$ from the top surface, for each hole. This procedure was repeated for three holes, drilled at same drilling parameters for statistical significance.

Next, surface roughness of drilled hole surface was measured using the Taylor Hobson CLI 2000 system based on non-contact measurement techniques. The drilled holes were cut in half through their thickness and measurements were taken on the central part of each side of the cut. This was repeated for three drilled holes for each combination of machining parameters. The roughness was measured axially for $7 \mathrm{~mm}$, leaving $1.5 \mathrm{~mm}$ from each side of the hole so that entry- and exit- hole delamination would not interact with the measurements. 


\subsubsection{Delamination measurement}

Measuring the extent of delamination induced by the drilling process is essential in determining structural integrity of the component during its lifetime. To measure delamination, X-ray micro-computed tomography $(\mu \mathrm{CT})$ was conducted to quantify the damaged area in CFRP in the vicinity of the drilled hole using a X-tech System ${ }^{\text {TM }}$ XTH-160 system. In these tests, each sample was exposed to X-ray radiation and rotated by $360^{\circ}$ about its vertical axis to capture images for 3-D reconstruction. The X-ray voltage and current were set at $80 \mathrm{kV}$ and $75 \mathrm{~mA}$, respectively. Delamination areas were measured at hole entry and exit employing a 1D delamination parameter $\left(\mathrm{F}_{\mathrm{D}}\right)$. This is defined as a ratio of the diameter of the circle that enclosed the damage area $\left(D_{\max }\right)$ to the nominal diameter of the drilled hole ( $D_{\text {nom }}$ ) (Fig. 3):

$$
\mathrm{F}_{\mathrm{d}}=\frac{\mathrm{D}_{\max }}{\mathrm{D}_{\mathrm{nom}}}
$$

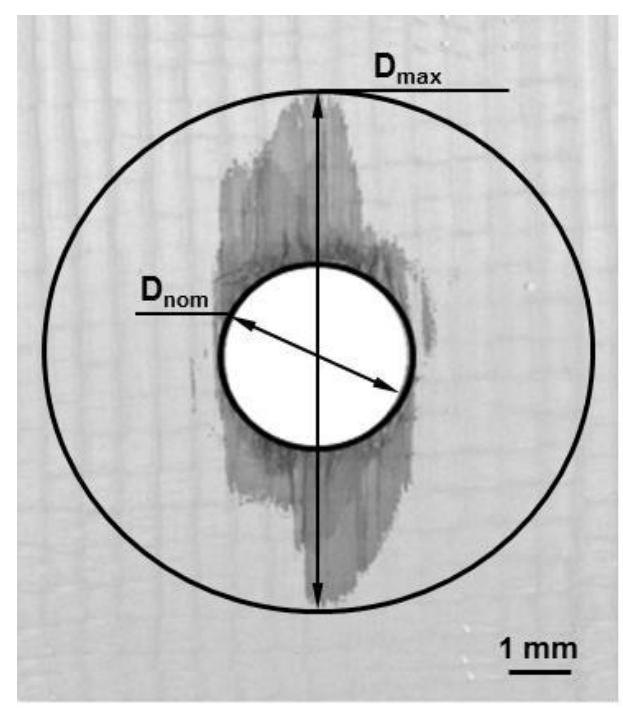

Figure 3: Delamination measurement [21]

\subsection{Methodology of drilling experiments}

For all drilling experiments the spindle speed was set at $40 \mathrm{rpm}$. A range of feed rate was studied- from $4 \mathrm{~mm} / \mathrm{min}$ to $20 \mathrm{~mm} / \mathrm{min}$ (specifically, 2, 4, 8, 12, 16 and $20 \mathrm{~mm} / \mathrm{min}$ ). Each test was repeated three times to ensure repeatability of the experiments. In tests, CD was carried out first followed by UAD. In the UAD regime, a tuned frequency of $27.8 \mathrm{kHz}$, with measured peak-to-peak amplitude of $12 \mu \mathrm{m}$ was employed at the drill tip in the axial direction. 
The literature suggested that the experiments may be conducted using the single drill bit for at least 25 holes $[16,17,18]$. Still for all experiments reported, except those in tool wear studies, the drill bit was changed after 3 holes to ensure that tool wear did not affect the machining results.

\subsection{Tool-wear studies}

Tool wear was measured as volume of material lost from the drill tool during the machining process. Surface topography analysis of the drill was carried out using the Alicona InfinteFocus Standard system. This system is a 3D optical microscope, employing focus variation to obtain 3D images of a scanned object. An objective of $5 x$ with a resolution of $23.48 \mu \mathrm{m}$ was used for all measurements; the collected 3D data was processed using Alicona IFM 3.5.01 software.

For all the tool wear-studies, the standard Jobber Carbide TiN coated drill was replaced with Jobber Carbide Guhring SL $5517 \varnothing 3 \mathrm{~mm}$ drill bits. This is due to the fact that TiN coating on the former drill bit was difficult to examine with the mentioned system because of a highly reflective surface of the drill-bit face. As a result, Guhring SL 5517 was preferred. All the measurements were repeated three times to gain sufficient statistical confidence for the obtained results. Before the start of the drilling process, the virgin tool was measured; consequently, post drilling, the tool was rescanned and the volume of drill material lost was accurately characterised, with high precision. 50 holes were drilled in $C D$ and UAD each at a feed rate of $8 \mathrm{~mm} / \mathrm{min}$ and $16 \mathrm{~mm} / \mathrm{min}$ with a spindle speed of $40 \mathrm{rpm}$. Wear measurements were performed for the same drill bit after drilling 10, 30 and 50 holes for each machining parameter.

\section{Results}

This section presents the experimental results obtained with UAD and CD. The magnitudes of drilling forces obtained with CD and UAD are compared and their effect on damage and drill quality discussed. Some evidence of brittle-to-ductile transition in the composite material subjected to high-frequency vibration in UAD was obtained.

\subsection{Cutting forces}


The cutting forces imposed by the cutting tool on the workpiece were recorded for UAD and $\mathrm{CD}$ for different machining parameters. The averaged thrust forces and torque during the period of complete engagement of the drill bit are reported. The signature of thrust forces and torques for $C D$ and UAD drilling are shown in Fig. 4. A significant reduction in the level of drilling torque was observed in UAD, not reported before. The maximum torque reduction in the case of UAD in drilling aluminium was as high as $80 \%$ when compared to $C D$ [19]. Our experiment is the first demonstration of such a drastic torque reduction in the ultrasonic drilling of CFRP.

For feed rates of $8 \mathrm{~mm} / \mathrm{min}$ and lower (Figs. 5a and b) a large reduction in thrust forces and drilling torque in UAD was observed when compared to CD. In order for UAD to be effective, the drill tool should disengage from the workpiece in each vibratory cycle. This intermittent, vibro-impact characteristic of the resulting process yields all the benefits of ultrasonic machining as previously observed in turning processes [20]. At higher feed rates, the drill remains fully engaged with the workpiece in UAD thus yielding effectively CD conditions resulting in the drilling forces identical to those in $C D$ (see Figs. $5 a$ and $b$ for $20 \mathrm{~mm} / \mathrm{min}$ ). 


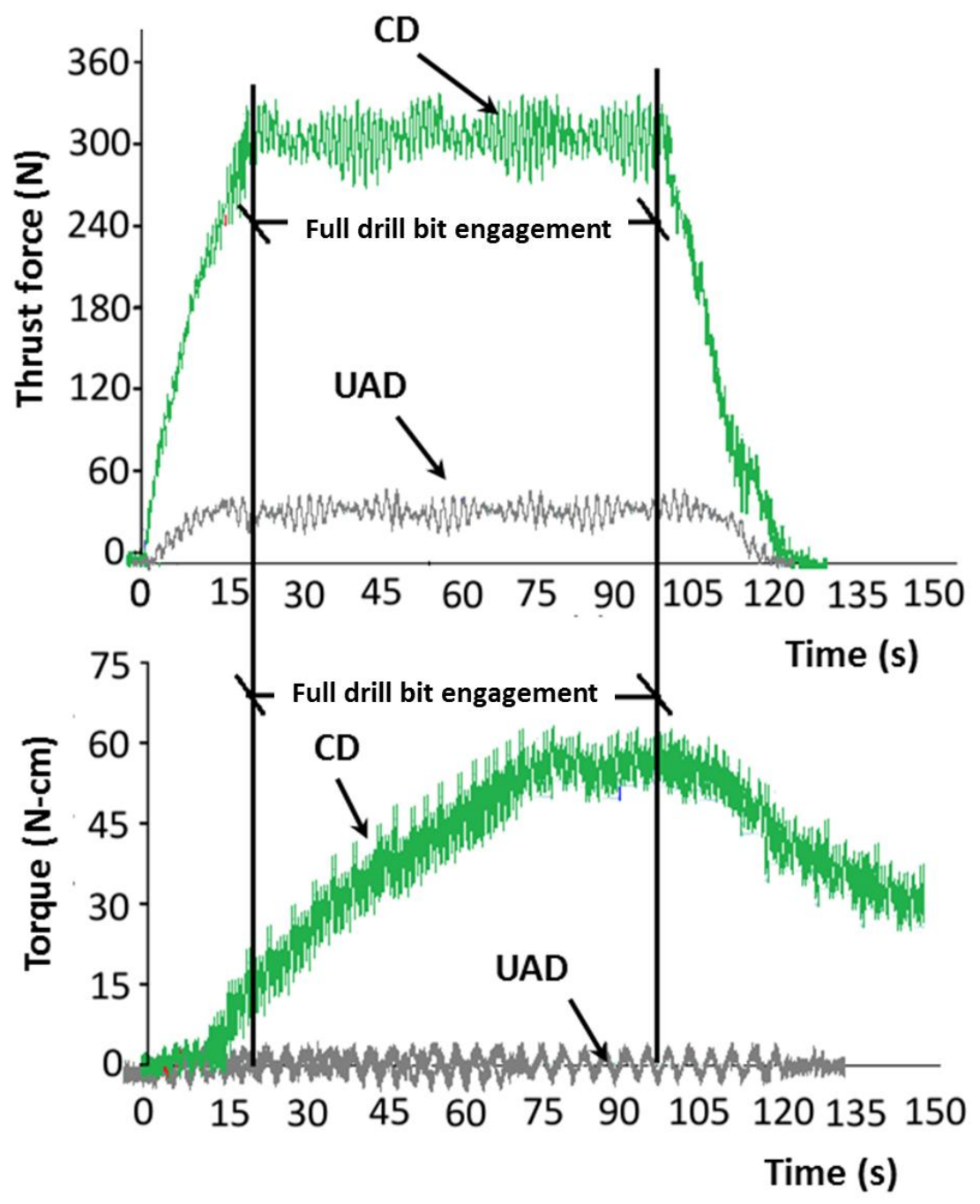

Figure 4. Evolution of thrust force and torque at $8 \mathrm{~mm} / \mathrm{min}$

The cause of force reduction in UAD has long been debated $[22,23,24]$ and explanation include the possibility of reduction of friction in UAD or/and reduction in the material hardness when subjected to ultrasonic vibration. 3D numerical simulations of the drilling processes, initially proposed in [21], and developed further as described in Section 4, were used to study some of the above hypothesis. Our studies indicate that frictional effects play a minimal role in force reduction. This study additionally indicates that there is a fundamental change in the physical behaviour of the material when subjected to ultrasonic vibration. 


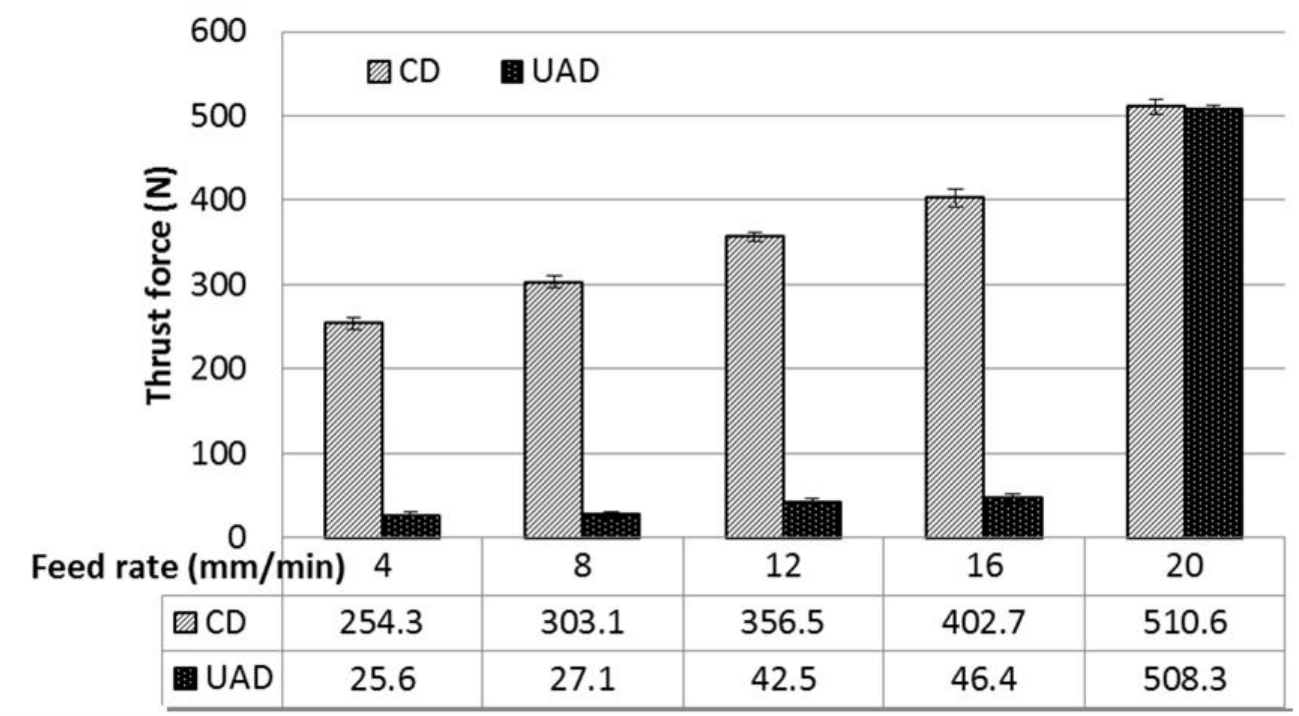

(a)

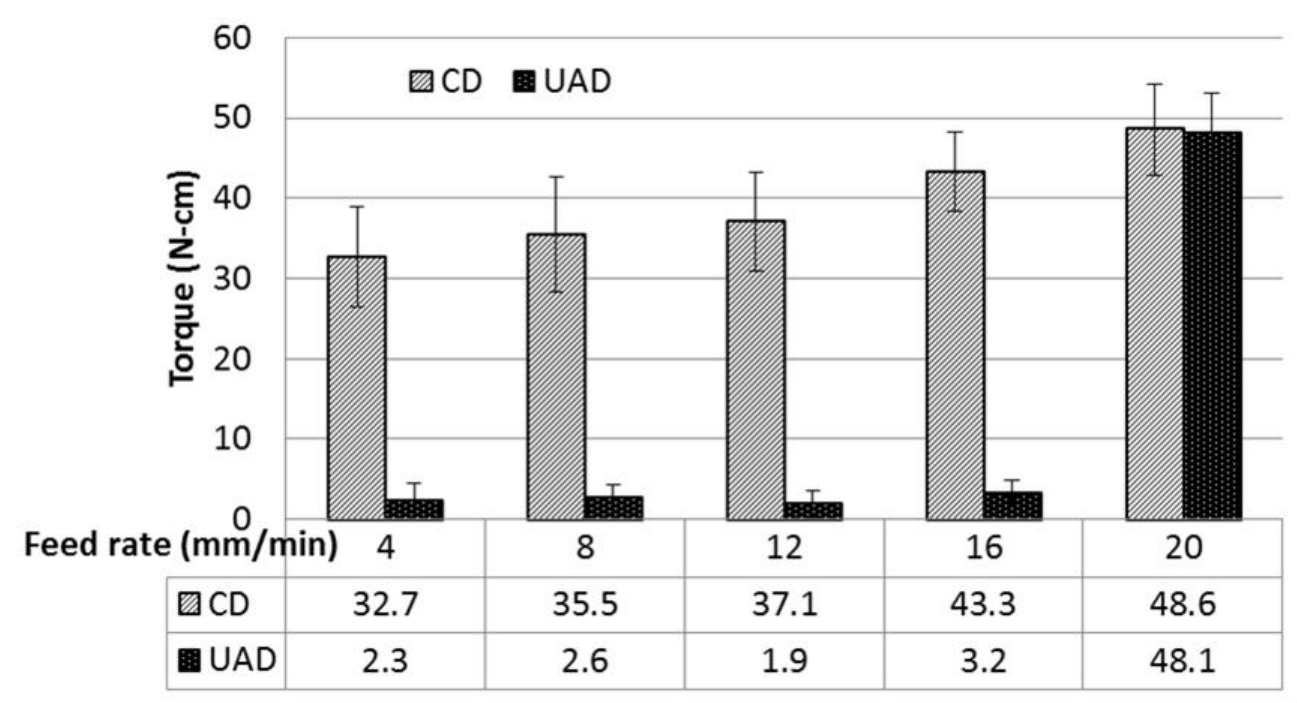

(b)

Figure 5: Comparison of magnitudes of thrust force (a) and torque (b)

The character of the torque trace in UAD warrants some discussion and analysis. The fact that this trace fluctuates about the axis of abscissas at lower feed rates indicates that UAD is fundamentally different from CD. Due to the very nature of the drilling process, a positive torque is expected, as the drill flutes perform an essential part of the cutting process; this was estimated to be a major contributing factor to the overall energy consumption in a conventional drilling process [25].

The fluctuating torque may be attributed to the coiling-uncoiling effect of the drill tool in a resulting coupled longitudinal and torsional mode of vibration at the purely axial excitation. 
The helical structure of the drill-bit flutes leads to winding/unwinding motion in the torsional direction when tension/compression vibration occur in the longitudinal direction.

\subsection{Chip formation}

A chip-formation process is often indicative of the underlying failure characteristics of the material. In our CD experiments, the chip formation was found to agree with the results previously reported in literature $[26,27]$, i.e. small-sized chips resemble crumpled fragments of CFRP, indicating the underlying brittle nature of the composite material (Figs. 6a, b, c). However, in UAD the formed-chip were long and helical, curled continuous chips similar to in conventional machining of ductile metals (Figs. $6 \mathrm{~d}, \mathrm{e}, \mathrm{f}$ ).

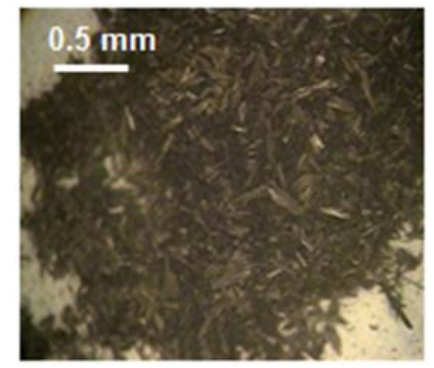

(a)

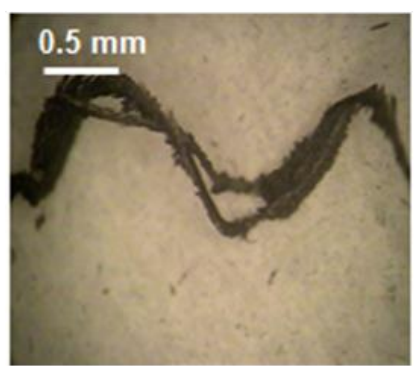

(c)

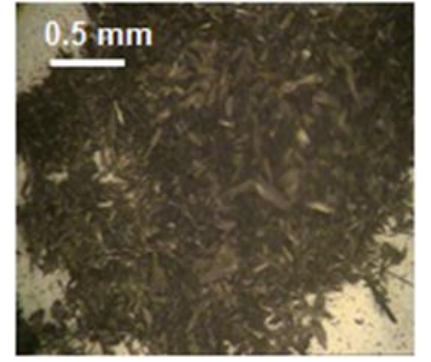

(b)

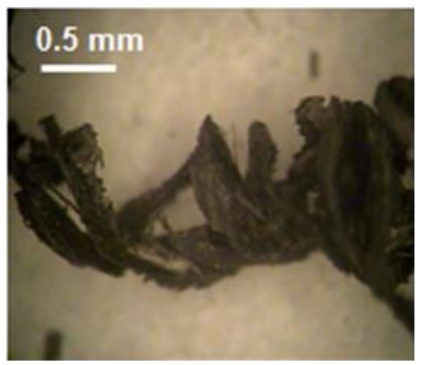

(d)

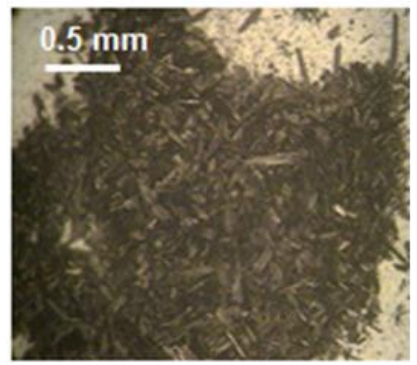

(c)

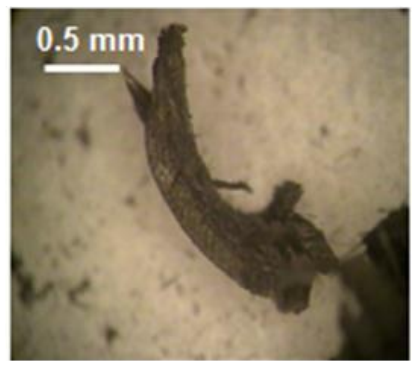

(e)

Figure 6: Optical microscopy of chips: (a) $C D$ at $4 \mathrm{~mm} / \mathrm{min}$; (b) $C D$ at $8 \mathrm{~mm} / \mathrm{min}$; (c) $C D$ at $16 \mathrm{~mm} / \mathrm{min}$; (d) UAD at $4 \mathrm{~mm} / \mathrm{min}$; (e) UAD at $8 \mathrm{~mm} / \mathrm{min}$; (f) UAD at 16 $\mathrm{mm} / \mathrm{min}$

This change in chip type could be attributed to various factors, with one of the main - apart of the intermittent character of tool-workpiece interaction - being the ultrasonic excitation. The studied CFRP with a thermoset matrix (epoxy) made remelting and subsequent solidification of chips not possible once the material is cured. Thus, further studies are warranted to understand the exact nature of the brittle-to-ductile transition in CFRP in UAD. 
In UAD, it was observed that the chip length varied depending on the feed rate. At lower feed rates long chips were observed (Fig. 6d) whereas at higher feed rates the chip was shorter in length (Fig. 6f).

\subsection{Thermal results}

In thermography tests, thermal camera was aligned to focus on the area in the immediate vicinity of the point of contact between the drill bit and the workpiece at the entry surface. This surface temperature was recorded throughout the drilling process with thermal distributions captured for both CD and UAD. Between each experiment, the workpiece was cooled down by pressurized air to room temperature to prevent the effect of pre-heating on the hole-making process. It was observed that the temperature increased during the test in both $C D$ and UAD.

The maximum measured surface temperature in UAD was $290.8^{\circ} \mathrm{C}$ whereas in $\mathrm{CD}$ it was $90.2^{\circ} \mathrm{C}$ for a drilling feed of $16 \mathrm{~mm} / \mathrm{min}$ (Figs. 7a, b). Further, Fig. 7c demonstrates the temperature evolution for both studied drilling techniques. The nominal temperature in $C D$ and UAD for various drilling feeds is shown in Fig. $7 \mathrm{~d}$.

Our experiments resulted in a few key observations for CD and UAD. First, the level of temperature in UAD is considerably higher than that in CD. Next, a linear increase in temperature, from $56^{\circ} \mathrm{C}$ to $90^{\circ} \mathrm{C}$, was observed with increasing feed rates in $\mathrm{CD}$. Such an effect was reported previously in several studies [28, 29]. However, in UAD the temperature rise to $265^{\circ} \mathrm{C}$ was almost constant irrespective of the feed rate (for $<20 \mathrm{~mm} / \mathrm{min}$ ). This is primarily, due to the process of repetitive impacting in UAD, which inevitably leads to temperature rise in the vicinity of the tool-workpiece interface. The almost constant temperature in UAD for a range of feed rates below $20 \mathrm{~mm} / \mathrm{min}$ implies that the local temperature rise was a direct effect of the imposed vibrations as long as tool separation occurred for each vibratory cycle. Once the critical feed rate was exceeded and the tool did not separate from the workpiece, conditions similar to those of CD were recovered, which reflected in the measured values of temperature and forces. 


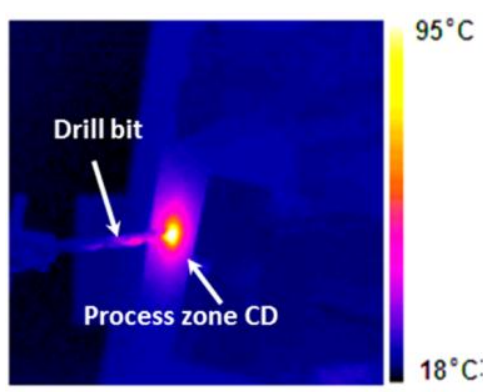

(a)

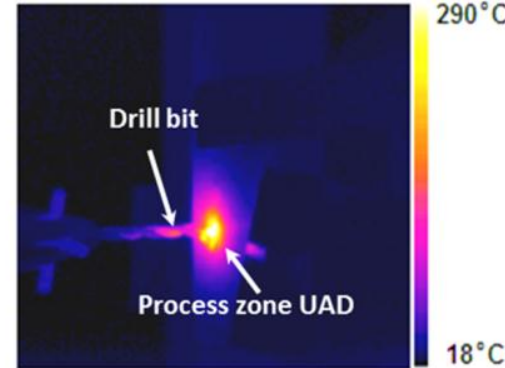

(b)

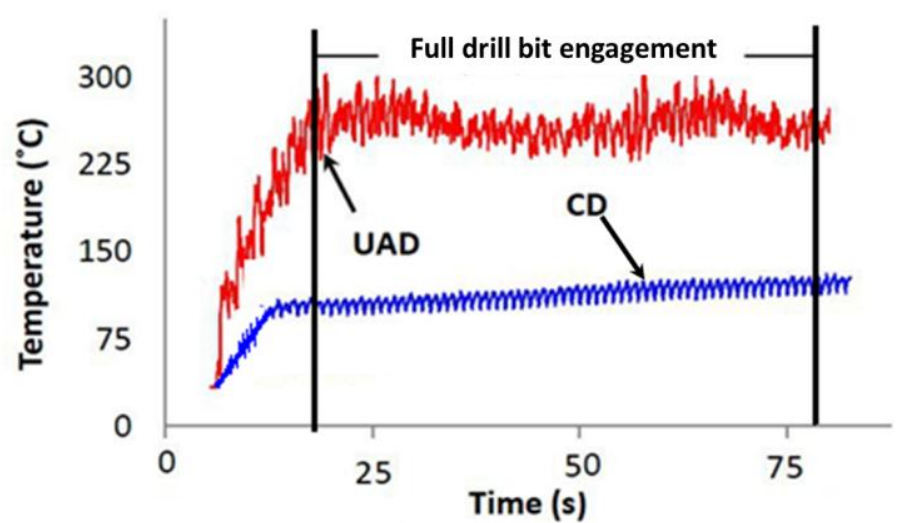

(c)

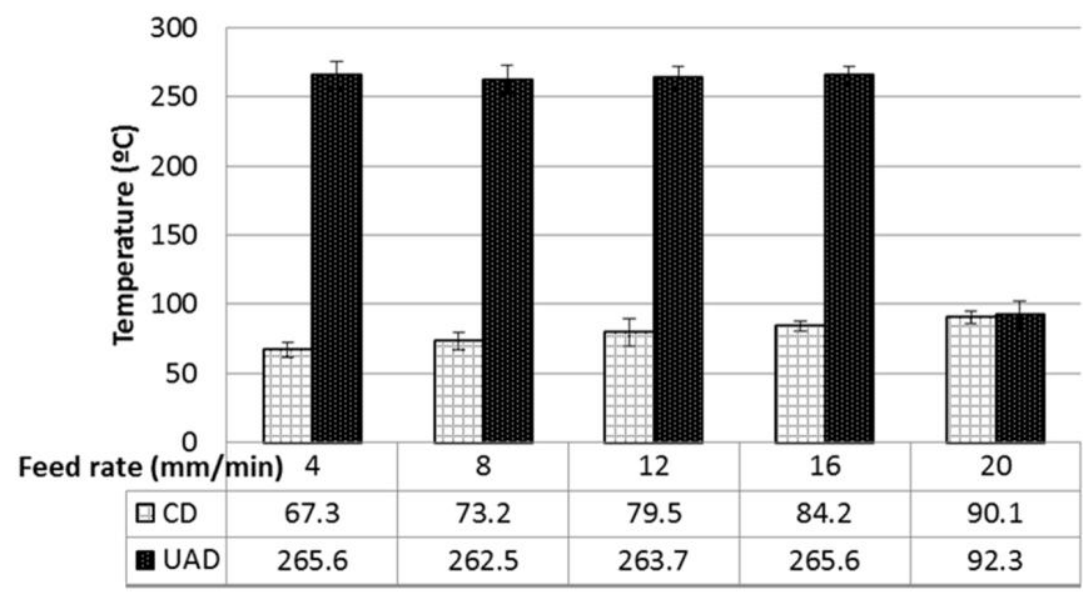

(d)

Figure 7: In-situ temperature measurements at $16 \mathrm{~mm} / \mathrm{min}$ : (a) snapshot with IR camera for CD; (b) snapshot with IR camera for UAD; (c) evolution of surface temperature; (d) surface temperature vs. feed rate

This level of increased temperature in UAD was observed for drill bit vibrating at a resonance frequency of $27.8 \mathrm{kHz}$. If the resonance frequency was the increase without a change in amplitude, we expect the process zone temperature to increase, since more vibration energy is pumped into the material. This hypothesis needs to be checked in the future with experiments conducted at a range of frequencies and amplitudes. Prior studies in ultrasonically assisted turning of metals show that increasing the frequency has greater benefits to increase of amplitudes. Such studies need to be conducted in UAD. 
The high measured temperature in UAD warrants careful analysis to ensure that thermal decomposition was not the major cause of the lowered machining forces. Thus, a further study, employing thermogravimetric was conducted.

\subsection{Thermogravimetric analysis}

Thermogravimetric analysis (TGA) is extensively practiced for thermal analysis of materials. TGA measures the amount and the rate of change in the weight of a material under study with respect to an increase in temperature. This method is used to observe thermal degradation of the material $[30,31]$.

A TGA (Q5000-IR) thermogravimetric analyser was used for the experiments. A virgin CFRP composite material sample cut into a size of $3 \mathrm{~mm} \times 3 \mathrm{~mm} \times 3 \mathrm{~mm}$ was placed into the analyser's heating chamber. The samples were heated at a rate of $10^{\circ} \mathrm{C} / \mathrm{min}$ in air atmosphere with an air intake rate of $25 \mathrm{ml} / \mathrm{min}$ (the manufacturer suggested these parameters for TGA of CFRP). The weight lost (in \%) with increasing temperature is shown in Fig. 8. No significant reduction in weight of the sample was observed from point $A$ to $B$, however, decomposition of the resin in the composite started at a temperature of $\sim 360^{\circ} \mathrm{C}$ (point B); this temperature corresponds well with prior findings [32]. The resin decomposed completely at $700^{\circ} \mathrm{C}$ (point $\mathrm{C}$ ). The remaining weight represents the fibre fraction in the composite since the decomposition of the carbon fibre starts in excess of $900^{\circ} \mathrm{C}$ [33]. The undertaken TGA analysis suggested that the epoxy did not burn during the UAD process as the measured temperature was considerably lower. However, the higher temperature in UAD may adversely affect the quality of the drilled workpiece. Thus, the circularity, roughness and delamination in the composite was characterised. 


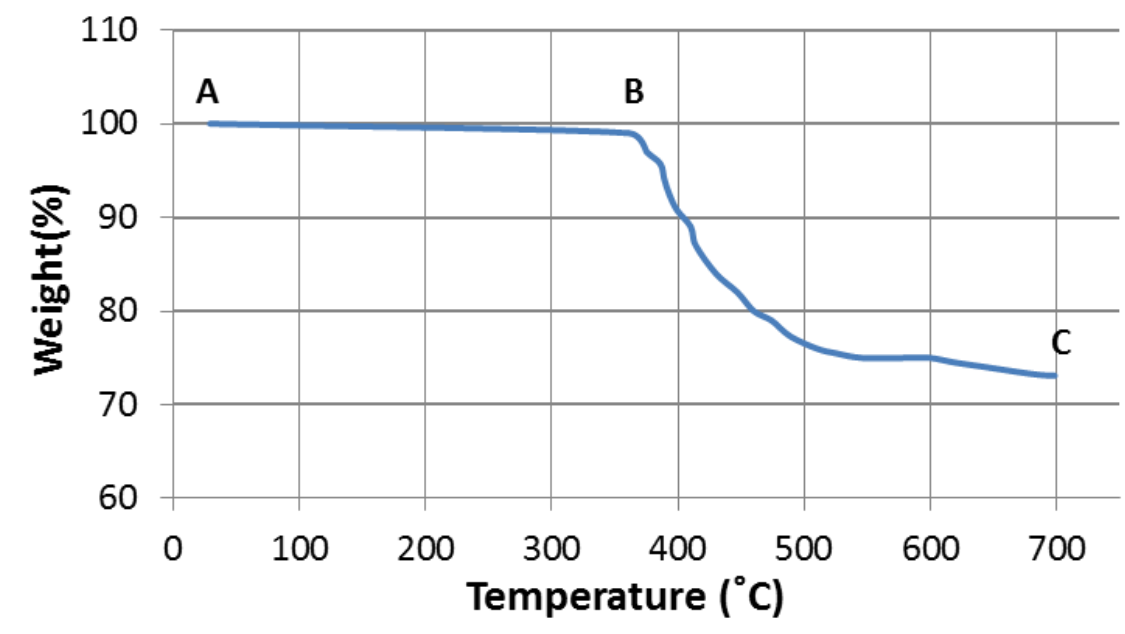

Figure 8: Thermogravimetric analysis of decomposition of CFRP with temperature

\subsection{Circularity}

Hole circularity was analysed for UAD and CD with various feed rates (Fig. 9a). At a lower feed rate of $4 \mathrm{~mm} / \mathrm{min}$, the circularity was improved in excess of $50 \%$ in UAD. However, with an increase in the feed rate, this improvement decreased to $30 \%$ at $20 \mathrm{~mm} / \mathrm{min}$. It means that improvement in circularity was consistently observed in UAD for all the used machining parameters. An interesting observation can be made for the feed rate of $20 \mathrm{~mm} / \mathrm{min}$. Although, the drilling forces show no difference in UAD and $C D$, considerable improvements in circularity were still measured indicating that ultrasonic drilling has the potential to demonstrate considerable advantage even at feed rates beyond the critical value. 


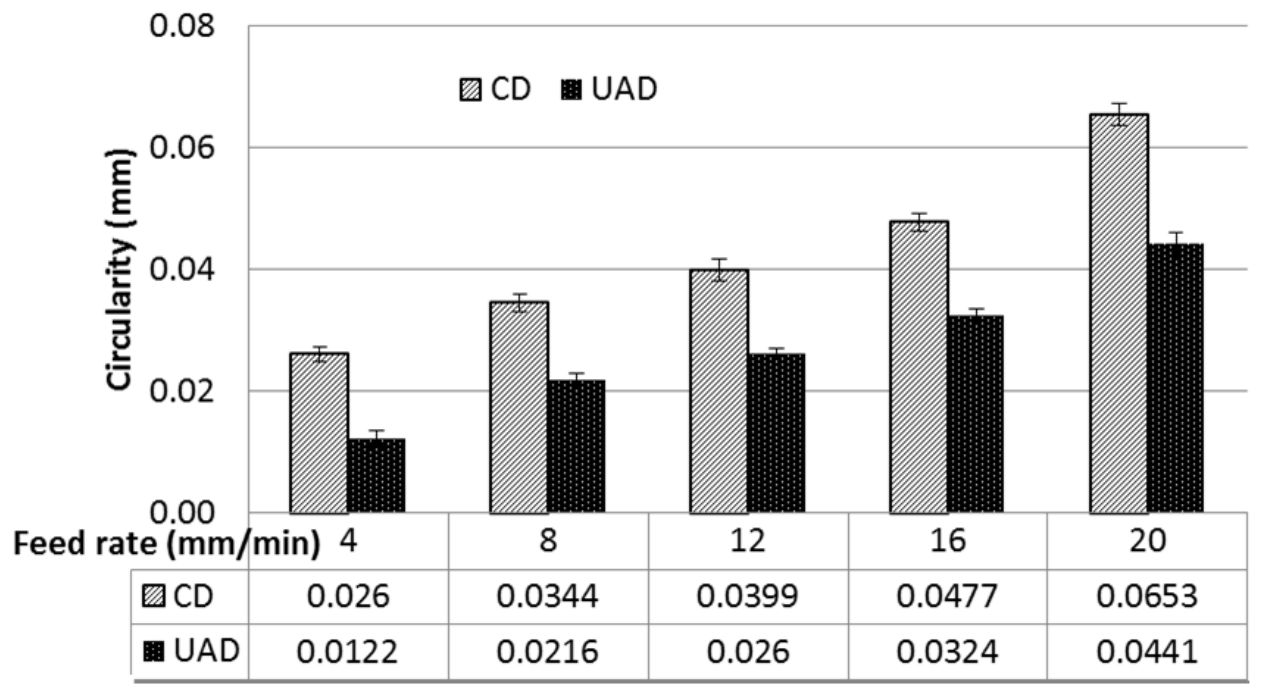

(a)

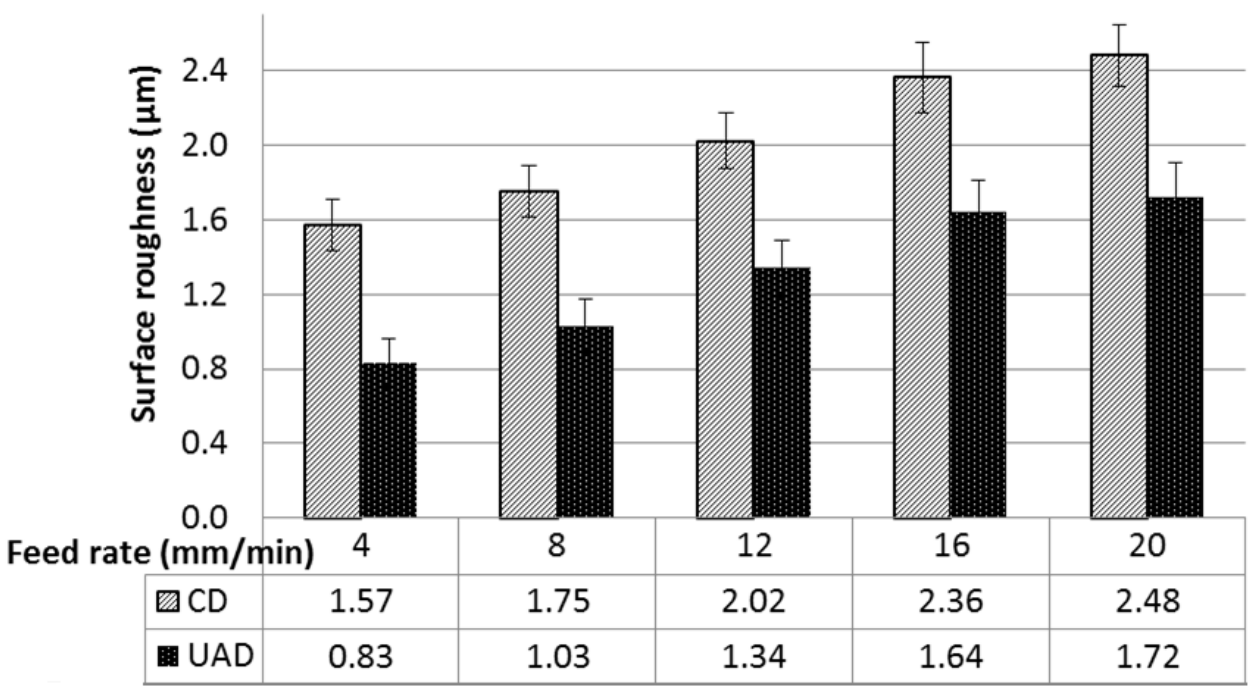

(b)

Figure 9: Feed rate vs. circularity (a); surface roughness (b)

\subsection{Surface roughness}

Next, the drilled holes were cut in half along the axial direction, and the surface roughness on the inner surface of the hole assessed. All measurements were taken along the same length of the hole surface. The arithmetic mean deviation parameter $R_{a}$, which is extensively used to assess surface quality in metrology, is reported here.

Surface roughness of holes drilled with UAD showed consistent improvement when compared to that for CD (Fig. 9b). Similar to the observations for hole circularity, surface roughness was observed to improve even for the feed rates that show no improvement in drilling forces in UAD. This is due to the nature of the UAD process, which inspite of no 
kinematic disengagement from the workpiece at higher feed rates, helps to improve the surface quality due to a polishing effect from multiple vibratory movement of the drill bit over the same surface area.

\subsection{Delamination}

The delamination factor was assessed for different feed rates used in UAD and CD (Fig. 10). Both drilling techniques demonstrated an increase in delamination with an increase in feed rate.

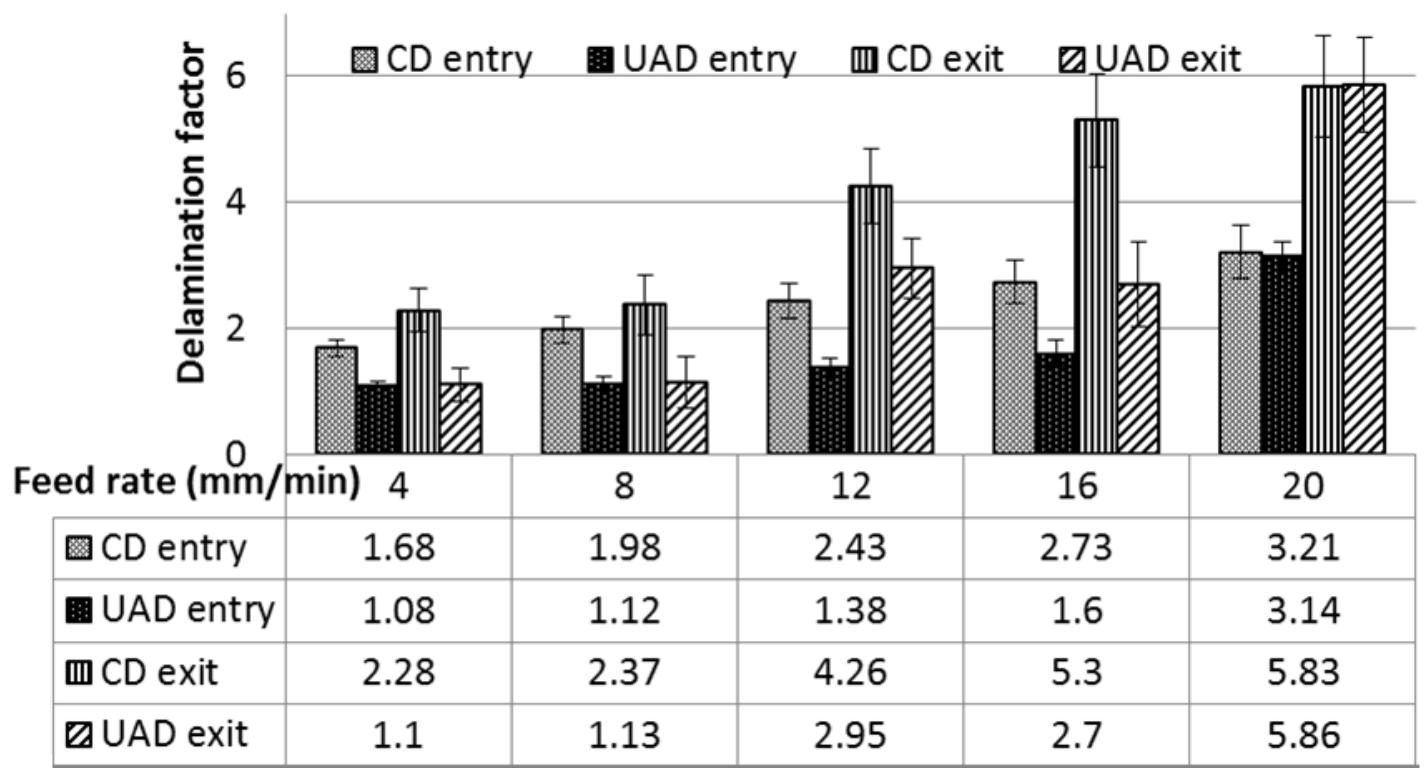

Figure 10: Feed rate vs. delamination factor

Additionally, exit delamination was higher than entry delamination in both processes. For a feed rate of $20 \mathrm{~mm} / \mathrm{min}$, delamination was observed to be identical in CD and UAD, which suggests that the drilling force has a direct influence on the damage induced in drilling, as was observed by many researchers for conventional drilling [34, 35, 36] even in UAD.

\subsection{Tool wear}

As mentioned above, the drill tool used in tool-wear analysis was different from that in other experimental studies. The volume of material lost from the drill is indicative of the net wear in the tool due to machining. Results of tool wear at $8 \mathrm{~mm} / \mathrm{min}$ and $16 \mathrm{~mm} / \mathrm{min}$ shows Fig. 11 that in UAD tool wear was sufficiently lower than that in CD. The finding that is a feed rate of $8 \mathrm{~mm} / \mathrm{min}$ tool wear was slightly higher in UAD after drilling 10 holes is not statistically significant; for a higher number of holes, the effect is evident. 


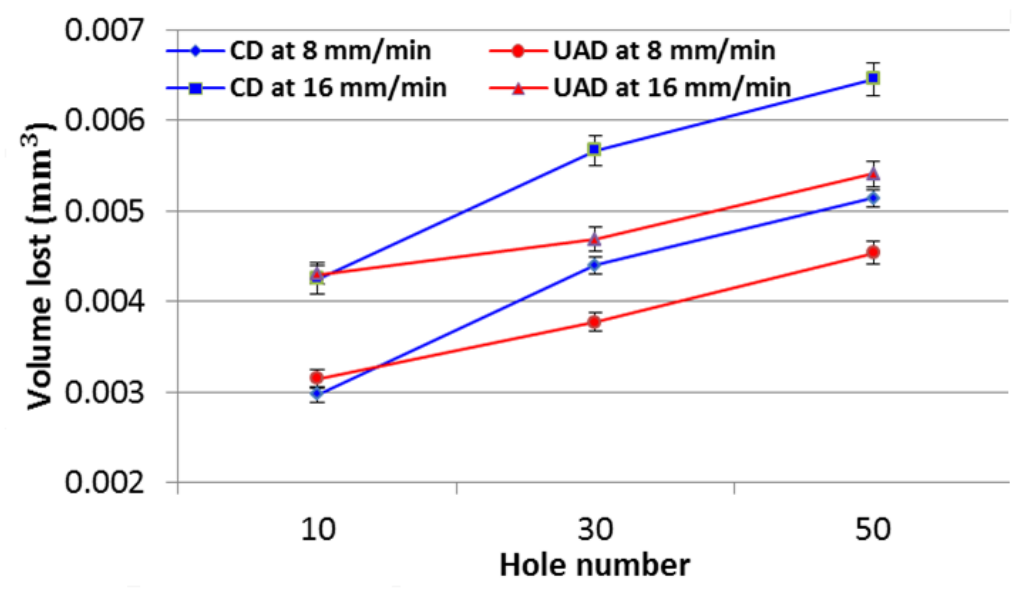

Figure 11: Evolution of volume lost with number of holes drilled

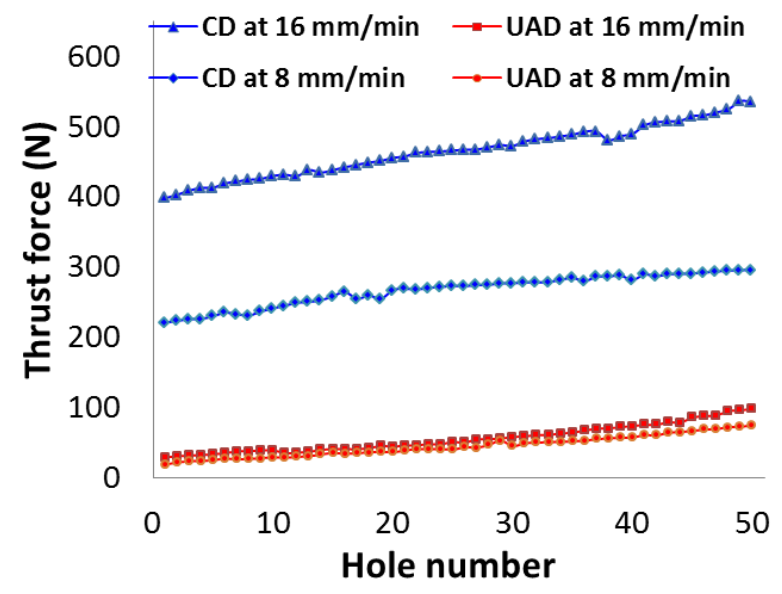

(a)

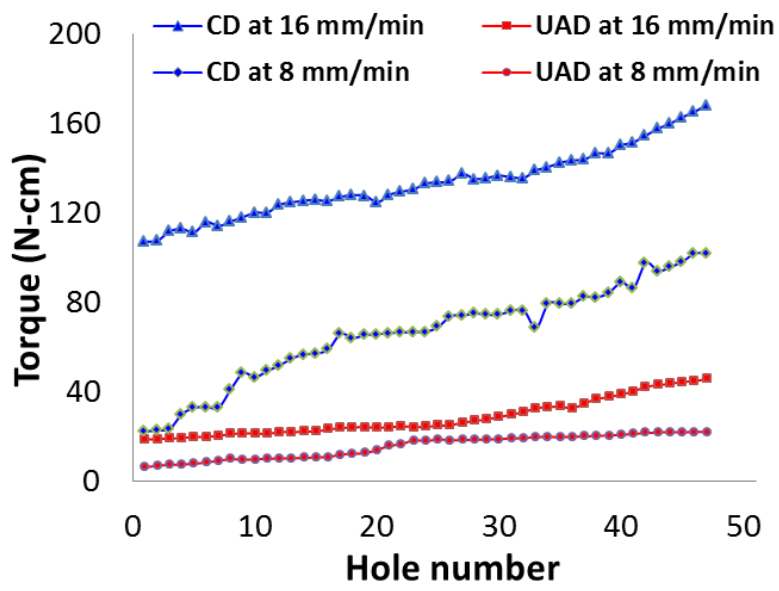

(b)

Figure 12: Evolution of thrust force (a) and torque (b) with number of drilled holes

Drill-wear typically affects the drilling forces, thus, the levels of thrust force and torque in CD and UAD for every hole drilled were recorded (Fig. 12). In drilling of CFRP, both thrust force and torque increased with increasing tool wear, as expected. It is noteworthy that the drilling force in UAD after the drilling of 50 holes is significantly lower than that in $C D$, implying that the damage sustained in the composite would be lower. Needless to say, more studies in tool wear needs to be carried out to study the phenomena in depth. However, our preliminary studies demonstrate some clear advantages of UAD over CD for CFRP.

\section{Finite-element analysis of UAD in CFRP}

A finite-element (FE) model, appropriately validated with experimental results, can be used as a convenient virtual tool to elucidate the effect of various process parameters on a workpiece. Here, the FE model of drilling of composites developed by authors [21] was 
extended to accommodate the material response of CFRP composites to drilling with superimposed ultrasonic vibration. The assumptions behind the constitutive modelling of this phenomenon, the setup of FE model of UAD of CFRP composites and obtained results are discussed in this section.

\subsection{Background and assumptions in material model}

UAD employs superposition of ultrasonic vibration onto the relative cutting motion between a drill bit and the workpiece drilled. This collective effect results in the substantial reduction in the drilling forces as discussed above. In this work, a 3D parametric model of UAD in CFRP laminate was developed in commercial software ABAQUS/Explicit [13]. This model accounted for acoustic and thermal softening of the CFRP workpiece during UAD. The mechanical behaviour of CFRP laminate was defined using the Hill's potential theory [38-39] for anisotropic materials together with the rate-independent plasticity criterion incorporating effects of ultrasonic softening. An element-removal scheme was used based on the shear damage-initiation criterion to replicate the hole-making process. The temperature rise due to plastic strain was modelled assuming adiabatic conditions. It should be noted that the temperature is a plastic-strain-work-conjugate in the adiabatic system; hence, an element was also removed from the mesh when instantaneous temperature reached the glass-transition limit of the epoxy matrix (irrespective of instantaneous plastic strain reaching the fracture strain), thus softening effectively the material at the macroscale.

The primary assumptions of this material model are:

- Instantaneous intensity of ultrasonic vibrations is proportional to plastic strain induced in the studied CFRP laminate. This intensity is defined in terms of ultrasonic energy per unit time transferred to the workpiece and is a function of instantaneous contact pressure between the drill bit and the workpiece, the frequency and amplitude of vibration.

- The strain-rate dependence of the CFRP laminate, especially in transverse and through-thickness directions, is small enough to be neglected owing to relatively low loading rates.

- The temperature rise in the CFRP laminate during its interaction with the vibrating drill tip is mainly due to plastic strain developed locally. 
The formulation of a constitutive material model incorporating acoustic softening in CFRP under the influence of ultrasonic vibration can be found in Phadnis et al. [14,37].

\subsection{FE model setup}

A 3D geometry of the $3 \mathrm{~mm}$ twist drill with a point angle of $118^{\circ}$ and helix angle of $31^{\circ}$ was modelled in Abaqus (Fig. 13). The drill was modelled as a rigid body, accounting for inertial effects. The mesh was optimized to reduce the computational cost without compromising accuracy. The mesh was refined in the immediate vicinity of the drilled area to capture high stress gradients during the drilling process. Elements in the refined cylindrical zone were removed when the failure criterion was met in numerical simulations. The laminated specimen was fixed at its four vertical faces, while the drill was constrained to rotate only about its own axis with a specified speed and feed. The FE analysis was performed with the experimentally optimised drilling parameters: spindle speed of $40 \mathrm{rpm}$, feed rate of $16 \mathrm{~mm} / \mathrm{min}$, vibration frequency of $27.8 \mathrm{kHz}$ and peak-to-peak vibration amplitude of $12 \mu \mathrm{m}$. In order to incorporate the vibrating boundary condition, a time-dependent sinusoidal movement representing ultrasonic vibration was imposed on the drill in the axial direction.

The contact and friction parameters used in the simulations were defined by a number of experimental factors such as cutting speed, feed rate, drill geometry and surface properties. Contact between the twist drill and the laminate was incorporated employing the general contact algorithm (based on the penalty-enforced contact method) available in Abaqus/Explicit. The coefficient of friction at the interface between drill's cutting edge and laminate was chosen as 0.03 based on the work of Lucas et al. [12] wherein ultrasonic cutting of epoxy resin was studied. This was assumed to be appropriate for UAD. We recognise that parameter identification for the UAD process is complicated and requires detailed parametric studies in the future.

The specimen of CFRP laminate was discretised into 820000 eight-node, first-order, reduced-integration hexahedral mesh elements of type C3D8R with the smallest element size of $5 \mu \mathrm{m}$. The drill was meshed with 35000 four-node, 3D discrete rigid elements of type C3D4 with the smallest element size of $125 \mu \mathrm{m}$. The computational 
time required was about 17 days on 12 Intel Xeon processors (64 bit) using a highperformance computing Hydra cluster, available at Loughborough University, UK.

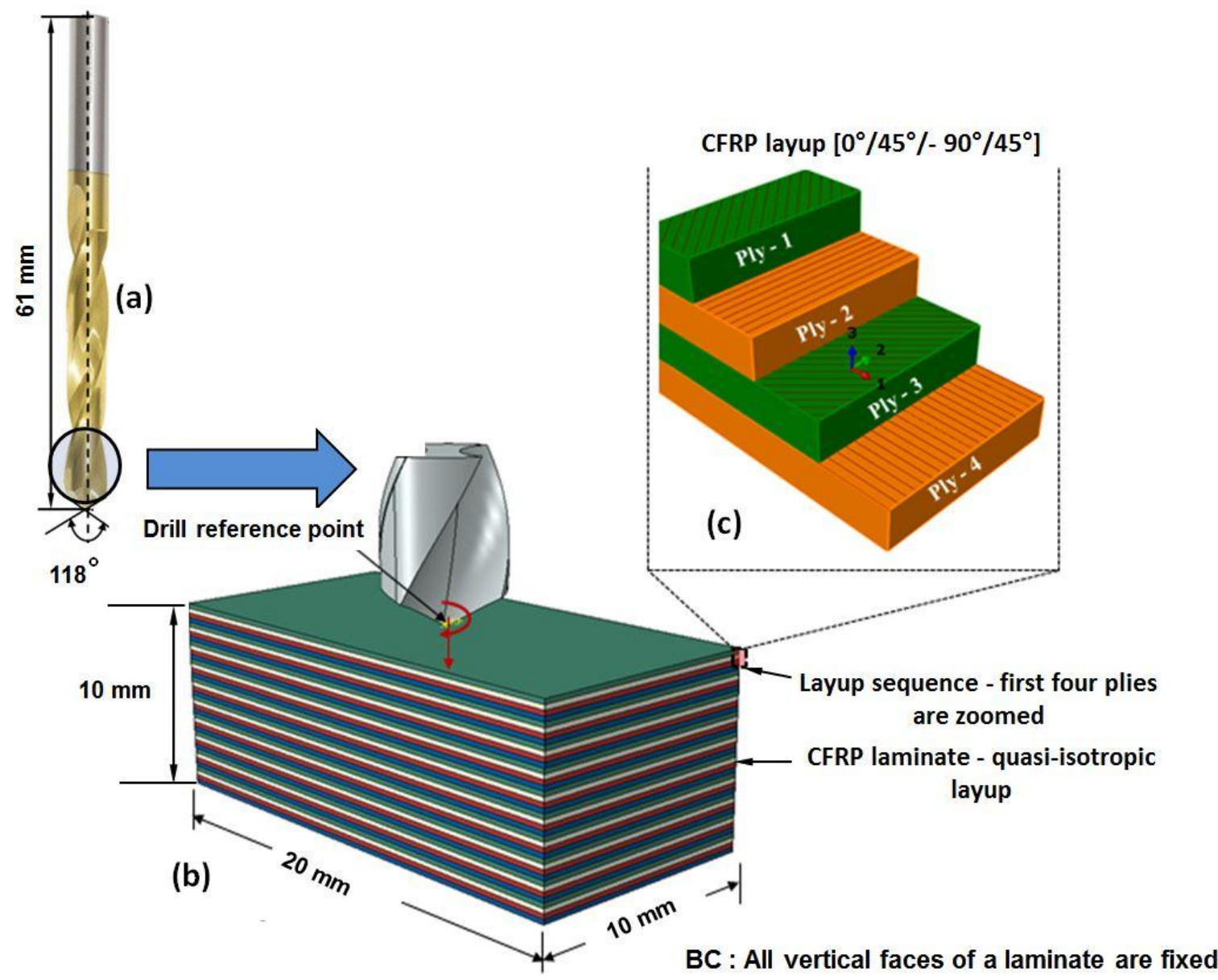

Figure 13: Schematic of FE model: (a) drill bit; (b) FE model; (c) composite layup

\subsection{Results: thrust force and torque}

The results obtained from FE simulations trace a change in the thrust force with time (or depth of penetration). The FE model predicts the level of thrust force and its evolution during UAD process reasonably accurately (Fig. 14a). The torque trace shows deviations from the experimental data. This may be attributed to discussed dynamics of the vibrating drill resulting in its winding/unwinding due to ultrasonic waves propagating in the excited drill. This mechanism was not incorporated in the FE model; as a result, a positive response of the torque was captured (Fig. 14b) in contrast to a near zero averaged torque measured in experiments. Still, it was significantly lower than the level measured (and modelled) for CD. 

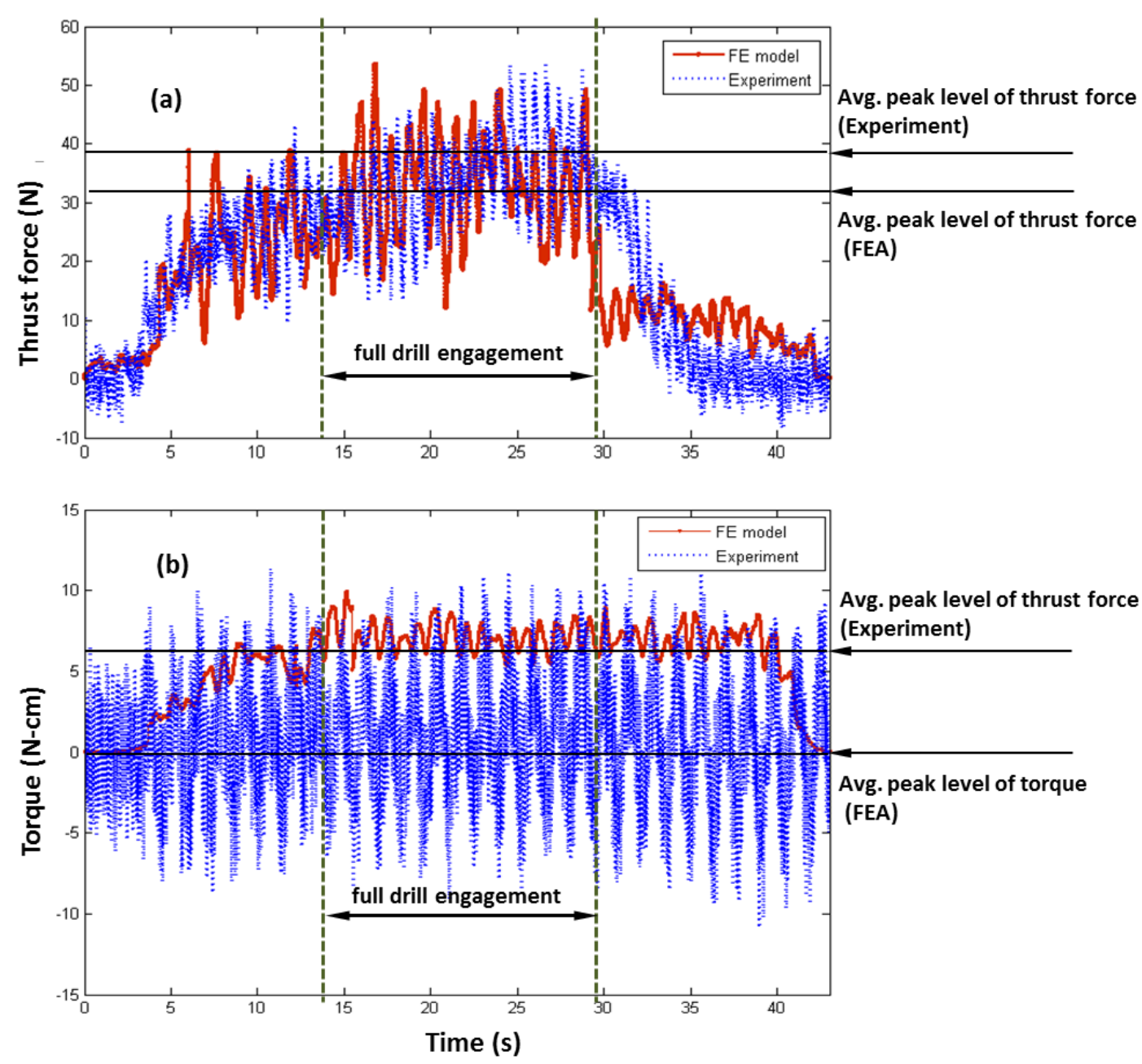

Figure 14: Comparison of FE results with experimental data: (a) thrust force; (b) torque

\section{Conclusion and outlook}

In this paper, a novel dry drilling technique - ultrasonically assisted drilling (UAD) - is presented for the drilling in carbon/epoxy composites. Its advantages in terms of drilling forces and quality of drilled holes were studied and qualified. An extensive experimental and numerical study of this process resulted in the following conclusions:

- A significant reduction in drilling forces (thrust force and torque often in excess of $80 \%$ when compared to a dry conventional drilling (CD) process, was observed. Prior studies [8-11] show improvements in UAD of metals and composites with the use of wider drills. 
- The holes drilled with UAD show better circularity, improved surface roughness and result in a lower delamination area in UAD when compared to CD. This effect was observed for feed rates below the critical feed rate of $20 \mathrm{~mm} / \mathrm{min}$.

- The temperature in the process zone in UAD was higher than that in $C D$; however, the measured temperature was still lower than the thermal-decomposition temperature of the epoxy matrix of the composite. Further studies are required to study the effect of thermal degradation (if any) on the composite integrity in UAD.

- A brittle-to-ductile transition occurred in the composite material subjected to ultrasonic vibration. This affected the type of chips formed during the machining process.

- A numerical model was developed accounting for ultrasonic softening effects in the material when subjected to UAD. The simulation results demonstrate good agreement with the drilling thrust forces. Noticeable deviations with regard to drilling torque results indicate that the drill dynamics (due to imposed ultrasonic vibrations) play an important role in cutting, which needs to be incorporated for accurate predictions.

\section{Acknowledgements}

The authors acknowledge the contribution of Arth Mistry for carrying out the tool-wear analysis. The authors would also like to acknowledge Engineering and Physical Sciences Research Council (EPSRC), UK for providing FLIR SC3000 system for thermal analysis.

\section{References:}

[1] E. Persson, I. Eriksson, L. Zackrisson, Effects of hole machining defects on strength and fatigue life of composite laminates. Composites Part A: Applied Science and Manufacturing 28 (1997) 141-151.

[2] H. Hocheng, C.C. Tsao, The path towards delamination-free drilling of composite materials. Journal of Materials Processing Technology 167 (2005) 251-264.

[3] H. Hocheng, C.C. Tsao, Comprehensive analysis of delamination in drilling of composite materials with various drill bits. Journal of Material Processing Technology 140 (2003) 335-339.

[4] A. Sadek, M. H. Attia, M. Meshreki, B. Shi, Characterization and optimization of vibration-assisted drilling of fibre reinforced epoxy laminates. CIRP Annals Manufacturing Technology 62 (2013) 91-94. 
[5] S. Arul, L. Vijayaraghavan, S-K. Malhotra, R. Krishnamurthy, The effect of vibratory drilling on Hole quality in polymeric composites. International Journal of Machine Tools and Manufacture 46 (2006) 252-259.

[6] H. Takeyama, S. Kato, Burrless drilling by means of ultrasonic vibration. Annals of the CIRP 40 (1991) 83-86.

[7] H. Paris, S. Tichkiewitch, G. Peigne, Modelling the vibratory drilling process to foresee cutting parameters. CIRP Annals 54 (2005) 367-370.

[8] F. Makhdum, L. T. Jennings, A. Roy, V. V. Silberschmidt, Cutting forces in ultrasonically-assisted drilling of carbon fibre-reinforced plastics. Journal of Physics: Conference Series 382 (2012).

[9] F. Makhdum, N. P. Nurdiyana, A Roy, V.V. Silberschmidt, Ultrasonically-assisted drilling of carbon fibre reinforced plastics. Solid State Phenomena 188 (2012) 170175.

[10] V. I. Babitsky, V. K. Astashev, A. Meadows, Vibration excitation and energy transfer during ultrasonically assisted drilling. Journal of Sound and Vibration 308 (2007) 805814.

[11] P. N. H. Thomas, V. I. Babitsky, Experiments and simulations on ultrasonically assisted drilling. Journal of Sound and Vibration 308 (2007) 815-830.

[12] Lucas M, MacBeath A, McCulloch E, Cardoni A. A finite element model for ultrasonic cutting. Ultrasonics (2006) 22 (44) 503-509.

[13] ABAQUS 6.11 User manual.2011. Dassault Systems. Rhode Islands, United States.

[14] V. A. Phadnis, F. Makhdum, A. Roy, V.V. Silberschmidt, Experimental and numerical investigations in conventional and ultrasonically assisted drilling of CFRP laminate. Procedia CIRP 1 (2012) 455-459.

[15] The Mathworks Inc. Matlab 10.1. Natick, MA2000

[16] X. Wang, P. Y. Kwon, C. Sturtevant, D. Kim, J. Lantrip, Tool wear of coated drills in drilling CFRP. Journal of Manufacturing Processes 15 (2013) 127-135.

[17] A. Faraz, D. Biermann, K. Weinert, Cutting edge rounding: An innovative tool wear criterion in drilling CFRP composite laminates. International Journal of Machine Tools and Manufacture 49 (2009) 1185-1196.

[18] D. Iliescu, D. Gehin, M. E. Gutierrez, F. Girot, Modeling and tool wear in drilling of CFRP. International Journal of Machine Tools and Manufacture 50 (2010) 204-213.

[19] H. Onikura, O. Ohnishi, J. Feng, T. Kanda, T. Morita, Effects of ultrasonic vibration on machining accuracy in microdrilling. Journal of the Japan Society for Precision Engineering 62 (1996) 676-680.

[20] V. I. Babitsky, A. V. Mitrofanov, V. V. Silberschmidt, Ultrasonically assisted turning of aviation materials: simulations and experimental study. Ultrasonics 42 (2004) 81-86. 
[21] V. A. Phadnis, F. Makhdum, A. Roy, V. V. Silberschmidt, Drilling in carbon/epoxy composites: Experimental investigations and finite element implementation. Composites Part A: Applied Science and Manufacturing 47 (2013) 41-51.

[22] V. K. Astashev, V. I. Babitsky, Ultrasonic Process and Machines: Dynamics, Control and Applications. Berlin Heidelberg New York 2007.

[23] V. P. Severdenko, V. V. Petrenko, The temperature conditions during opendie upsetting of steel in an ultrasonic field. Izv. Akad. Nauk. B.S.S.R, 1969.

[24] O. Izumi, K. Oyama, Y. Suzuki, Effect of superimposed ultrasonic vibrations on the compressive deformation of metals. Transaction of Japan Institute of Metal 7 (1966) 162-167.

[25] R. Li, P. Hegde, A. J. Shih, High-throughput drilling of titanium alloys. International Journal of Machine Tools and Manufacture 47 (2007) 63-74.

[26] A. Koplev, A. Lystrup, T. Vorm, The cutting process, chips, and cutting forces in machining CFRP. Composites 14 (1983) 371-376.

[27] X. Wang, L. J. Wang, J. P. Tao, Investigation on thrust in vibration drilling of fibrereinforced plastics. Journal of Materials Processing Technology 148 (2004) 239-244.

[28] K. Weinert, C. Kempmann, Cutting temperatures and their effects on the machining behaviour in drilling reinforced plastic composites. Advanced Engineering Materials 6 (2004) 684-689.

[29] S. Rawat, H. Attia, Wear mechanisms and tool life management of WC-Co drills during dry high speed drilling of woven carbon fibre composites. Wear 267 (2009) 1022-1030.

[30] B. Stuart, Polymer Analysis. West Sussex, England: John Wiley and Sons Ltd. 2003.

[31] S. Lampman, Characterization and Failure Analysis of Plastics. Ohio, USA: ASM Publishers 2003.

[32] C. S. Wu, Y. L. Liu, Y. C. Chiu, Y. S. Chiu YS, Thermal stability of epoxy resins containing flame retardant components: an evaluation with thermogravimetric analysis. Polymer Degradation and Stability 78 (2002) 41-48.

[33] H. Wang, Q. Guo, J. Yang, Z. Liu, Y. Zhao, J. Li, Z. Feng, L. Liu, Microstructural evolution and oxidation resistance of polyacrylonitrile-based carbon fibers doped with boron by the decomposition of B4C. Carbon 56 (2013) 296-308.

[34] J. Pyo, Kim-G. Woo, Lee-K. Yong, Critical thrust force at delamination propagation during drilling of angle-ply laminates. Composite Structures 68 (2005) 391-397.

[35] G. W. Kim, K. Y. Lee, Critical thrust force at propagation of delamination zone due to drilling of FRP/metallic strips. Composite Structures 69 (2005) 137-141. 
[36] C. C. Tsao, Effect of induced bending moment (IBM) on critical thrust force for delamination in step drilling of composites. International Journal of Machine Tools and Manufacture 59 (2012) 1-5.

[37] V. A. Phadnis, A. Roy, V. V. Silberschmidt, A finite element model of ultrasonically assisted drilling in carbon/epoxy composites. Procedia CIRP 8 (2013) 141-146.

[38] R. Hill, Constitutive modelling of orthotropic plasticity in sheet metals. Journal of the Mechanics and Physics of Solids 38(3) (1990) 405-417.

[39] R. Hill, The Mathematical Theory of Plasticity: Clarendon Press 1998. 